\title{
Visceral and subcutaneous abdominal adiposity and pulmonary function in 30- year-old adults: a cross-sectional analysis nested in a birth cohort
}

\author{
Paula Duarte de Oliveira ${ }^{1 *}$, Fernando César Wehrmeister ${ }^{1}$, Bernardo Lessa Horta ${ }^{1}$, Rogelio Pérez-Padilla ${ }^{2}$, \\ Giovanny Vinícius Araújo de França ${ }^{3}$, Denise P. Gigante', Fernando C. Barros ${ }^{4}$, Ken K. Ong ${ }^{5}$, \\ Emanuella De Lucia Rolfe ${ }^{5}$ and Ana Maria Baptista Menezes ${ }^{1}$
}

\begin{abstract}
Background: Several studies have verified body fat distribution in association with pulmonary function (PF), mainly waist circumference, but few have used measures able to distinguish abdominal fat compartments. The present study aims to verify the association of visceral adipose tissue (VAT) and subcutaneous adipose tissue (SAT) with PF measures.

Methods: In 1982, all hospital births occurring in Pelotas, Brazil, were identified and those livebirths have been followed. In 2012-13, the cohort participants were evaluated and VAT and SAT measured using ultrasound; forced expiratory volume in the first second $\left(\mathrm{FEV}_{1}\right)$ or forced vital capacity $(\mathrm{FVC})$ were patronized in z-scores stratified by sex. The associations were verified using crude and adjusted linear regressions.

Results: The present analyses comprised 3438 individuals (1721 women). VAT was inversely associated with spirometric parameters, in both crude and adjusted models. SAT showed inverse associations in the crude analyzes in males and a positive trend after adjustment, except for SAT and FVC in males. To each centimeter of VAT, mean adjusted $\mathrm{FEV}_{1}$ z-scores decreased $0.072(95 \% \mathrm{Cl}-0.107 ;-0.036)$ in men and $0.127(95 \% \mathrm{Cl}-0$. $164 ;-0.090)$ in women, and FVC z-scores decreased $-0.075(95 \% \mathrm{Cl}-0.111 ;-0.039)$ and $0.121(95 \% \mathrm{Cl}-0.158$; -0.083 , in men and women, respectively.
\end{abstract}

Conclusions: VAT has a consistent inverse association with FEV 1 and FVC in both sexes. On the other hand, SAT showed inconsistent results with PF parameters.

Keywords: Pulmonary function, Body composition, Abdominal adiposity, Visceral adiposity

\section{Background}

Many studies have shown negative influences of obesity on pulmonary function (PF) in the last decades [1]. These findings have been attributed to the load imposed by the adipose tissue on the ventilatory mechanics [2-4], or to an adverse impact of obesity on the respiratory control, and more recently to systemic inflammation caused by excess of fat that could lead to airway

\footnotetext{
* Correspondence: pauladuartedeoliveira@gmail.com

${ }^{1}$ Federal University of Pelotas - Postgraduate Program in Epidemiology, Rua Marechal Deodoro, 1160, $3^{\circ}$ andar, Pelotas, RS Zip code: 96020-220, Brazil

Full list of author information is available at the end of the article
}

inflammation and subsequent airflow obstruction [4]. However, most of these studies measured body mass index, which is incapable to distinguish adipose tissue from other body components [5]. In addition, the upper body fat mass seems to play a more important role on PF impairment $[1,4,6]$, and measures such as waist circumference (WC), even having a high correlation with abdominal fat [5], cannot differentiate visceral adipose tissue (VAT) from subcutaneous adipose tissue (SAT).

Few studies [3, 7-11] with conflicting results, have utilized devices capable to separate abdominal VAT and SAT to verify its association with PF, such as computed 
tomography $(\mathrm{CT})$ or ultrasound. CT is the gold-standard device, but demands high costs and radiation risks and it is unfeasible in many research scenarios. As a more accessible device, abdominal ultrasound has demonstrated precise results on adipose tissue measures, presenting a good correlation with CT measures $(r=0.68-0.74)$ [5, 7]. To our knowledge, ultrasound was used in only two previous studies on this issue, in specific women samples $[8,9]$.

The present study aims to verify the association of VAT and SAT, measured by abdominal ultrasound, with spirometric function in a young adult population that have been prospectively followed since birth.

\section{Methods}

In 1982, the maternity hospitals in Pelotas, southern Brazil, were visited daily and the deliveries were identified. Those liveborns whose family lived in the urban part of the city were examined and their mothers interviewed. These subjects have been prospectively followed. In 2012-13, we tried to contact the cohort members, who were invited to visit the study clinic. After signing the informed consent form, the subjects were interviewed, examined and donated a blood sample. The 30 years follow-up project was approved by the Federal University of Pelotas Ethics Committee under protocol 16/12. More details on the methodology of the cohort study are described in previous publication [12].

For the purposes of the current report, a crosssectional analysis was performed using data from all cohort participants who had spirometry information at 30 years follow-up. The exclusion criteria for spirometry were: mental problems not allowing the understanding of the testing procedures, the self report of pregnancy, active tuberculosis, heart disease, recent surgery (thoracic, abdominal, or ocular in the previous 3 months), and recent retinal detachment (3 months). The spirometric variables analyzed were the Forced Expiratory Volume in the first second
$\left(\mathrm{FEV}_{1}\right)$ and the Forced Vital Capacity (FVC) prior to the bronchodilator use. Both were assessed with a portable ultrasonic spirometer (EasyOne, Ndd Medical Technologies Inc., Zürich, Switzerland). We followed the procedures recommended by the American Thoracic Society/European Respiratory Society [13], aiming for three acceptable maneuvers with a maximum variation of $150 \mathrm{~mL}$ between the two highest values.

In the 2012-13 visit, we also assessed subcutaneous abdominal adipose tissue (SAT) and visceral adipose tissue (VAT) thicknesses using an abdominal ultrasound (Toshiba Xario, Toshiba Medical Systems Corp, Tokyo, Japan). The probe was placed at the crossing point between the xyphoid line and the waist circumference using electronic callipers. SAT was defined as the distance on the sagittal plane between posterior line of dermis to the outer bowel wall and VAT as the distance from the peritoneum boundary to the lumbar spine (in millimeters) [14, 15] Two different static images were obtained at the end of a quiet expiration by applying minimal pressure, ensuring no displacement of the abdominal cavity. As previously described [16] three trained technicians performed the ultrasound scans using a standardized protocol, and all measurements were performed immediately after obtaining each image (Figure 1). Quality control procedures were conducted during the data collection. Quality control sessions were carried out in order to estimate the intra and inter-observer technical errors by comparing the results obtained by each of the three technicians to those of one investigator (GVAF) who had been previously trained and certified in this technique. Three sessions were conducted before starting data collection, with 10 participants each. The relative inter-observer technical error of measurement was 3.1\% for both measures, while the relative intra-observer technical error of measurement for VAT was $4.1 \%$ and $3.4 \%$ for SAT, as described in previous publication [17]. This data were collected by two trained radiology technicians.

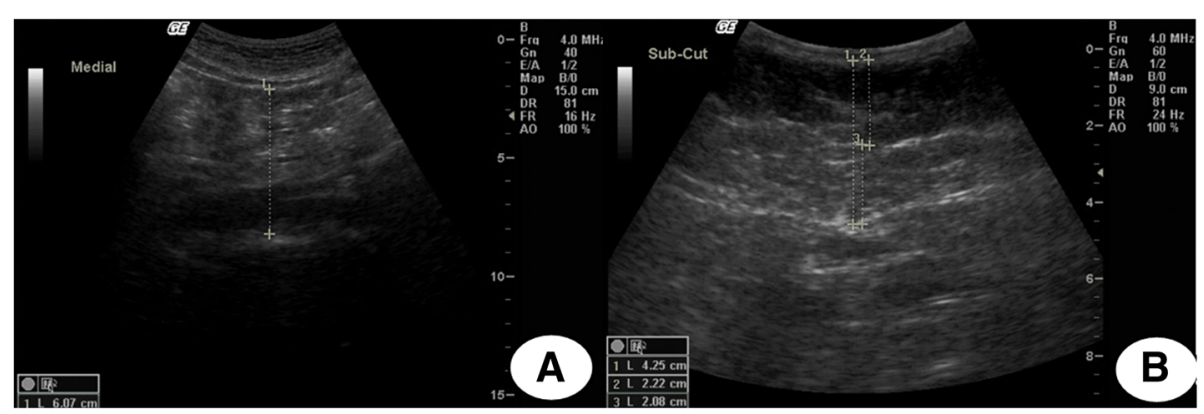

Fig. 1 Ultrasound image examples to abdominal adipose tissue measurement. a visceral adipose tissue thickness. b subcutaneous adipose tissue thickness and components (deep and superficial) 
The analyses were performed using software Stata version 12.2 (Stata Corp., College Station, TX, USA). The variables were described using mean and standard deviation for continuous variables and absolute and relative frequencies for categorical variables. Also, the correlations between the continuous variables (PF and body variables) were verified. The associations between VAT or SAT and $\mathrm{FEV}_{1}$ or FVC were evaluated using linear regressions and, due to the significant interaction between sex and abdominal fat variables, analyses were stratified by sex. The linearity of the associations was verified using fractional polynomial regressions (results not shown in the tables), indicating that the linear regression model was not different from the best model fitted with exponentials. $\mathrm{FEV}_{1}$ and FVC results were expressed as z-scores, which were generated from the standardized residuals of the study sample, taking into account skin color and height, stratified by sex.

In the multivariate model birth weight (in grams), maternal smoking during pregnancy, actual height (measured by stadiometer, in centimeters), total fat mass (percentage in relation to total mass, measured using air displacement plethysmography, BOD POD ${ }^{\circ}$ Composition System; COSMED, Albano Laziale, Italy), weight (in kilograms, measured by the BOD POD scale), skin color (self-reported in white, black, brown and others), schooling (complete years in formal education), family socioeconomic level (National Economic Index [18]), smoking at 30 years (never smoker, former smoker, smoker), self-reported wheezing in last year, any kind of corticosteroid use in the last 3 months and habitual physical activity (minutes spent in leisure-time activities per week), were included. All variables were collected at 30 years follow-up visit (except birth weight and maternal smoking during pregnancy) and selected for the adjusted model, a priori, by statistical and/or theoretical criteria (see Additional file 1: Table S1). Also, VAT and SAT were included simultaneously in the model. The variation inflation factor was verified to ensure the absence of collinearity between the model variables (variation inflation factor $<10$ ) and the only variable removed from the adjusted analyses was WC. Values of $p<0.05$ in the Wald's test for linear tendency were considered statistically significant.

\section{Results}

In 2012-13, 3701 subjects were evaluated, which added to the 325 known to have died, represented a follow-up rate of $68.1 \%$. Data on spirometry was available for 3438 individuals (1721 women) who were included in the present report. The quality criteria according to the American Thoracic Society/European
Respiratory Society guidelines [13] were met in $91.6 \%$ of the exams. The characteristics of the individuals included in the analyses were similar to those included in the initial cohort regarding sex and socioeconomic level (data not shown in tables), ensuring general population representativeness.

Table 1 shows the description of the sample regarding perinatal, socioeconomic, demographic, behavior, body composition and PF characteristics, stratified by sex. Most of the individuals were white $(75.1 \%$ and $76.4 \%$, men and women, respectively) and had 12 or more years of schooling $(39.0 \%$ and $48.8 \%$, men and women, respectively). Most of the sample had never smoked; $13.3 \%$ of men and $16.5 \%$ of women reported wheezing episodes in the previous year to the interview. Women had higher total fat mass compared to men (37.3 versus $24.5 \%$ ); on the other hand, men had higher mean VAT than women (6.9 versus $4.9 \mathrm{~cm})$. Concerning the spirometry, men had mean $\mathrm{FEV}_{1}$ and FVC $1.1 \mathrm{~L}$ and $1.3 \mathrm{~L}$, respectively, higher than women. Exposure to smoking during intrauterine life and skin color were the only variables without significant statistical difference between sexes.

The correlations between VAT, SAT, PF and other body variables are shown in Table 2 . It can be observed that the two abdominal fat variables have a lower correlation between them compared with other body fat variables.

Figures 2 and 3 shows the associations between VAT, SAT and PF parameters. We observed the same VAT trends for both sexes: consistent inverse association with $\mathrm{FEV}_{1}$ and FVC, in both crude and adjusted models. Regarding the adjusted analyzes for the several confounders, for each additional centimeter of VAT, mean adjusted $\mathrm{FEV}_{1}$ z-scores decreased 0.072 $(95 \%$ CI $-0.107 ;-0.036)$ in men and 0.127 (95\% CI $-0.164 ;-0.090)$ in women, and FVC z-scores decreased -0.075 (95\% CI $-0.111 ;-0.039)$ and 0.121 (95\% CI $-0.158 ;-0.083)$, in men and women, respectively. These $z$-score results represent, in absolute values, mean $\mathrm{FEV}_{1}$ decrease of $43 \mathrm{~mL}$ and $64 \mathrm{~mL}$ and FVC $60 \mathrm{~mL}$ and $61 \mathrm{~mL}$, in men and women, respectively, for each centimeter increment of VAT.

SAT showed different patterns of association with PF. Regarding the crude analyzes, we can observe inverse associations only among men. On the other hand, after adjustment, men and women showed positive associations between SAT and both PF parameters (except for SAT and FVC in men, but in the same trend - Figs. 2 and 3).

\section{Discussion}

The main result to be highlighted is that increases in VAT were strong predictors of reduced spirometric 
Table 1 Description of the sample as covariates, nutritional status, abdominal adiposity and lung function. 1982 Pelotas Birth Cohort $(n=3438)$

\begin{tabular}{|c|c|c|c|}
\hline $\begin{array}{l}\text { Social, demographic, } \\
\text { behavioral variables } \\
\text { and nutritional status }\end{array}$ & $\begin{array}{l}\text { Male } \\
(n=1717) \\
\mathrm{N}(\%)\end{array}$ & $\begin{array}{l}\text { Female } \\
(n=1721) \\
\mathrm{N}(\%)\end{array}$ & $p$ \\
\hline Birth weight (grams) ${ }^{a}$ & & & 0.003 \\
\hline$>=2500$ & $1614(94.0)$ & $1572(91.4)$ & \\
\hline$<2500$ & $103(6.0)$ & $148(8.6)$ & \\
\hline $\begin{array}{l}\text { Maternal smoking during } \\
\text { pregnancy }\end{array}$ & & & 0.932 \\
\hline No & $1115(64.9)$ & $1120(65.1)$ & \\
\hline Yes & $602(35.1)$ & $601(34.9)$ & \\
\hline Skin color & & & 0.121 \\
\hline White & $1290(75.1)$ & $1315(76.4)$ & \\
\hline Black & $274(16.0)$ & $274(15.9)$ & \\
\hline Brown & $95(5.5)$ & $80(4.7)$ & \\
\hline Others & $58(3.4)$ & $52(3.0)$ & \\
\hline Education (years) & & & $<0.001$ \\
\hline $0-4$ & $103(6.1)$ & $102(6.0)$ & \\
\hline $5-8$ & $381(22.4)$ & $290(17.0)$ & \\
\hline $9-11$ & $551(32.5)$ & $481(28.2)$ & \\
\hline$\geq 12$ & $662(39.0)$ & $833(48.8)$ & \\
\hline Smoking status & & & 0.008 \\
\hline Never & $978(57.0)$ & $1040(60.5)$ & \\
\hline Former & $296(17.2)$ & $312(18.2)$ & \\
\hline Smoker & $443(25.8)$ & $366(21.3)$ & \\
\hline Wheezing in the last year & & & 0.009 \\
\hline No & $1488(86.7)$ & $1437(83.5)$ & \\
\hline Yes & $229(13.3)$ & $284(16.5)$ & \\
\hline $\begin{array}{l}\text { Use of corticoids in the } \\
\text { last three months } s^{b}\end{array}$ & & & $<0.001$ \\
\hline No & $1576(95.5)$ & $1480(89.9)$ & \\
\hline Yes & $75(4.5)$ & $167(10.1)$ & \\
\hline Physical activity in leisure & & & $<0.001$ \\
\hline Inactive & $1040(61.7)$ & $1341(79.0)$ & \\
\hline Active & $646(38.3)$ & $356(21.0)$ & \\
\hline Nutritional status (body mass index) & & & $<0.001$ \\
\hline Underweight & $25(1.5)$ & $44(2.6)$ & \\
\hline Normal weight & $610(35.7)$ & $772(45.0)$ & \\
\hline Overweight & $697(40.7)$ & $493(28.7)$ & \\
\hline Obese & $379(22.2)$ & $407(23.7)$ & \\
\hline $\begin{array}{l}\text { Anthropometric, adiposity } \\
\text { and pulmonary function } \\
\text { variables }\end{array}$ & Mean (SD) & Mean (SD) & $P^{*}$ \\
\hline Height (cm) & $174.4(6.9)$ & $161.4(6.2)$ & $<0.001$ \\
\hline Weight (kg) & $82.2(16.8)$ & $69.6(16.2)$ & $<0.001$ \\
\hline Waist circumference & $89.2(11.8)$ & $80.6(12.0)$ & $<0.001$ \\
\hline Total fat mass (\%) & $24.5(9.2)$ & $37.3(8.5)$ & $<0.001$ \\
\hline
\end{tabular}

Table 1 Description of the sample as covariates, nutritional status, abdominal adiposity and lung function. 1982 Pelotas Birth Cohort $(n=3438)$ (Continued)

\begin{tabular}{llll}
\hline $\begin{array}{l}\text { Social, demographic, } \\
\text { behavioral variables } \\
\text { and nutritional status }\end{array}$ & $\begin{array}{l}\text { Male } \\
(n=1717) \\
\mathrm{N}(\%)\end{array}$ & $\begin{array}{l}\text { Female } \\
(n=1721)\end{array}$ & $p$ \\
\hline N (\%) & \\
\hline Subcutaneous adipose tissue (cm) & $1.9(1.0)$ & $2.6(1.2)$ & $<0.001$ \\
Visceral adipose tissue (cm) & $6.9(2.0)$ & $4.9(1.7)$ & $<0.001$ \\
FEV $_{1}$ (liters) & $4.0(0.6)$ & $2.9(0.5)$ & $<0.001$ \\
FVC (liters) & $4.8(0.8)$ & $3.5(0.5)$ & $<0.001$
\end{tabular}

$N$ number of observations, $S D$ standard deviation, $B M I$ body mass index, $F E V_{1}$ forced expiratory volume in the first second, FVC forced vital capacity ${ }^{a}$ Variables collected in the perinatal follow up, other variables at 30 years

${ }^{b}$ Maximum number of missing values: 104 observations in corticoids use ${ }^{c}$ Cutoff point for physical activity - $150 \mathrm{~min} /$ week as recommended by the World Health Organization for adults. $P$-value by qui-squared test ${ }^{*} p$-value by t-test

measures, in both sexes, more importantly in women. In order to explore the effects of each abdominal fat compartment independently, multivariate models including VAT and SAT were utilized, since correlation between them was low ( $r=0.39$ for men and women). As mentioned previously, measures such as WC are more accessible, but cannot differentiate abdominal compartments, which is the main objective of this study. WC and PF results, as other body measures in this same population, can be found in previous publication [19]; the present findings are in accordance with other previous studies that had investigated central obesity by different measure methods and research settings $[20,21]$.

Similar results using $\mathrm{CT}$ to assess abdominal fat were observed by Park et al. among Korean individuals aged 15 to 85 years [11]: in women, an increase in VAT was associated with reduced PF, while in men the best predictor of reduced lung function was total abdominal adipose tissue, VAT and SAT, after adjustment for height, weight, age, WC, systolic blood pressure and inflammatory markers, not using VAT and SAT in the same model.

We used ultrasound measurements of abdominal as proxies for these abdominal fat masses. While the validity of ultrasound in this specific setting has not yet been determined, some validation studies using the same standardized protocol have found strong correlations between ultrasound and magnetic resonance imaging estimates of abdominal fat in a variety of settings and populations $[14,22,23]$. A strict quality control process was carried out and we could identify consistent sex differences in the distribution of these abdominal fat compartments compared with previous reports using other imaging methods [14, 22, 24-27].

The role of the adipose tissue is not limited to lipids deposit. There is also evidence of its role as endocrine organ, producing a number of proinflammatory molecules and cytokines such as 
Table 2 Correlation between body composition variables and pulmonary function, stratified by sex

\begin{tabular}{|c|c|c|c|c|c|c|c|}
\hline & $\mathrm{FEV}_{1}$ & FVC & VAT & SAT & WC & $\begin{array}{c}\text { Total fat } \\
\text { mass }\end{array}$ & Weight \\
\hline $\mathrm{FEV}_{1}$ & & 0.894 & -0.241 & -0.004 & -0.065 & -0.115 & 0.090 \\
\hline FVC & 0.898 & & -0.191 & 0.010 & -0.012 & -0.096 & 0.144 \\
\hline VAT & -0.171 & -0.166 & & 0.3923 & 0.673 & 0.543 & 0.586 \\
\hline SAT & 0.034 & 0.030 & 0.387 & & 0.804 & 0.809 & 0.778 \\
\hline WC & 0.020 & 0.041 & 0.727 & 0.762 & & 0.824 & 0.915 \\
\hline Total fat mass & -0.144 & -0.146 & 0.645 & 0.786 & 0.847 & & 0.815 \\
\hline Weight & 0.165 & 0.187 & 0.622 & 0.731 & 0.926 & 0.750 & \\
\hline
\end{tabular}

Grey cells - males correlations. FEV ${ }_{1}$ forced expiratory volume in the first second, FVC forced vital capacity, SAT subcutaneous adipose tissue, VAT visceral adipose tissue, WC waist circumference

inteleuncine- 6 and C-reactive protein, the last found in high levels in the ones with high VAT accumulation and highly related to cardiovascular episodes $[28$, 29]; VAT has been also known as insulin resistant compartment [30]. On the other hand, SAT has controversial findings regarding its role on the diseases risk. In non-caucasian populations this compartment showed associations with several metabolic changes [31-33], but in recent studies it showed a protective effect and lack of association in obese individuals [34, 35].

The two main hypotheses for PF reduction due to excess of abdominal fat are via inflammatory mediators [4] and/or by mechanical restriction [2-4]. Whether the reduced lung function is due to one or the other cannot be completely clarified in our study, we can just have clues that the mechanical restriction seems to be more important, since reduction of both parameters, $\mathrm{FEV}_{1}$ and FVC, were observed.

VAT has been associated to several cardiometabolic risk factors, metabolic syndrome and systemic inflammation [30]. However, two previous studies [3, 11] investigated abdominal fat compartments using $\mathrm{CT}$ and reduced lung function, but neither of them supported the inflammation hypothesis: no association was found between inflammatory markers and PF [3] or persistence of the association between abdominal adiposity with lower PF after controlling for some

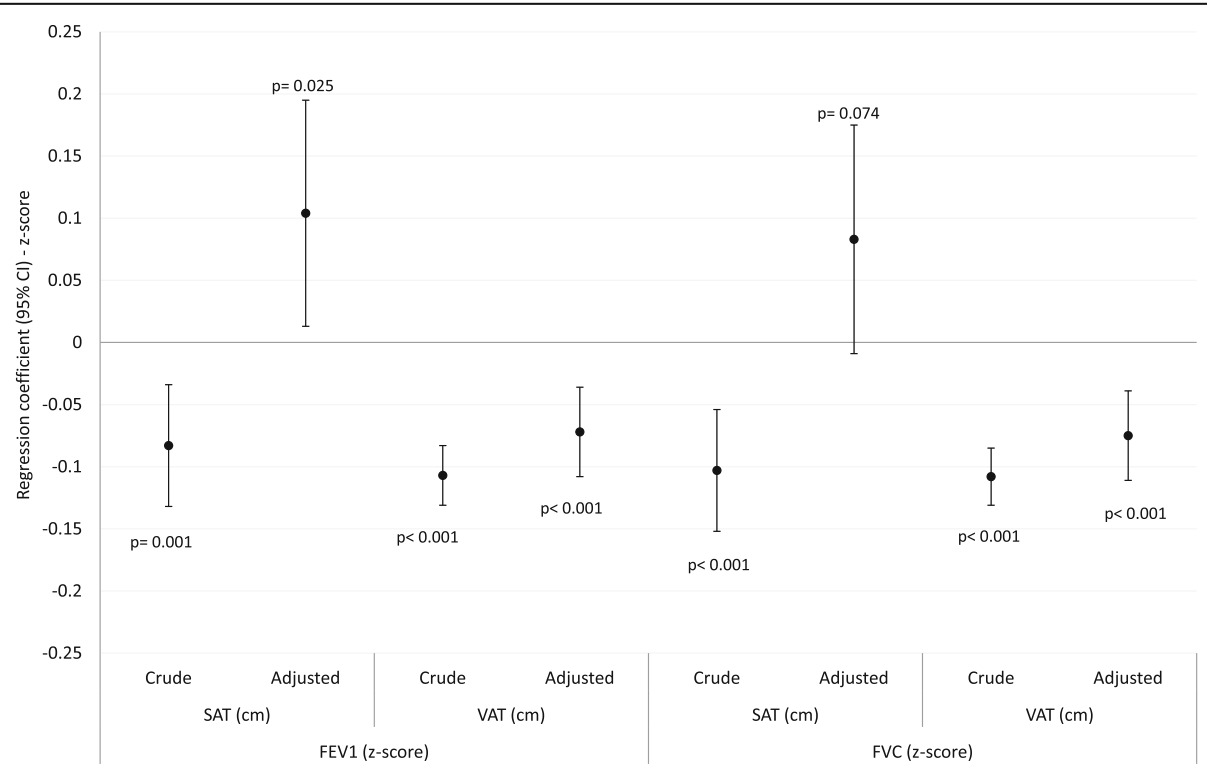

Fig. 2 Linear regressions: spirometric measures ( $z$-scores) and abdominal fat, males $(n=1701)$. SAT: subcutaneous adipose tissue; VAT: visceral adipose tissue; FEV1: forced expiratory volume in the first second; FVC: forced vital capacity; Cl: confidence interval; Adjusted by subcutaneous or visceral fat, weight, total fat mass (\%), asset index, scholarship (complete years), smoking status (never, former, active smoker), self-reported wheezing in the last year, corticoids use in the last three months, physical activity, birth weight and maternal smoking during pregnancy. P-values: Wald's test for linear tendency 


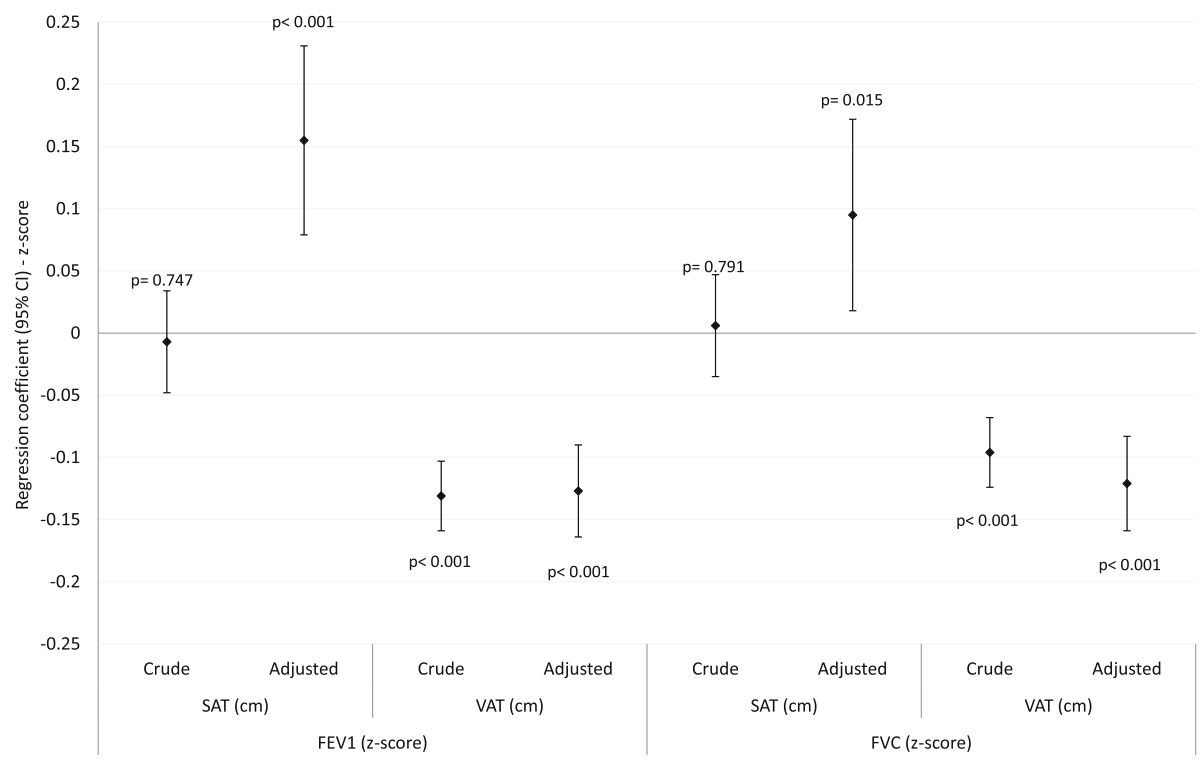

Fig. 3 Linear regressions: spirometric measures (z-scores) and abdominal fat, females ( $n=1712)$. SAT: subcutaneous adipose tissue; VAT: visceral adipose tissue; FEV1: forced expiratory volume in the first second; FVC: forced vital capacity; Cl: confidence interval; Adjusted by subcutaneous or visceral fat, weight, total fat mass (\%), asset index, scholarship (complete years), smoking status (never, former, active smoker), self-reported wheezing in the last year, corticoids use in the last three months, physical activity, birth weight and maternal smoking during pregnancy. P-values: Wald's test for linear tendency

inflammatory makers in the adjusted statistical model [11].

SAT showed an inverse association with PF in previous publications $[3,8,11]$. In our study, we observed positive associations between SAT and PF after adjustment and this result must be interpreted carefully due to the lack of plausibility that SAT increment can be beneficial to PF. In our population, the mean SAT is still low at 30 years old and could lead to an absence of influence on reduction of PF parameters. Also, SAT accumulation has been associated with a normal metabolic profile, while VAT accumulation, considered ectopic, is associated with an altered metabolic profile due to habits such as smoking and low physical activity [30]. This might explain this SAT positive trend, mainly after adjustment for VAT and total fat mass. Only one study we are aware of [10], using CT in an elderly population, did not find association concerning VAT, SAT and PF, although they had find an inverse association between PF and central obesity measured by dual-energy X-ray absorptiometry.

Some strengths of our study should be mentioned. We used a large general population sample, with information for several confounding factors. This allows us power to detect the associations and extrapolate results to similar healthy populations. Also we had rigorous quality control in spirometry and ultrasound measures, a method that allows a good estimation of adiposity compartments (VAT and SAT) despite the literature on adiposity measured by US and FP is scarce.

On the other hand, we did not perform any static lung volume measures, such as total lung capacity or expiratory reserve volume; we have just spirometric measurements, more accessible in this research scenario than methods based on plethysmography or inert gas dilution. Although spirometric and traditional anthropometric measurements were performed several times during cohort follow-ups, abdominal ultrasound measurements were carried out only at the 30th year followup allowing just cross-sectional analysis between abdominal fat compartments and PF outcomes preventing us to infer causality.

\section{Conclusion}

In this 30-years-old general population sample, VAT showed an inverse association with PF reduction, with consistent results between crude and adjusted analysis, $\mathrm{FEV}_{1}$ and FVC and both sexes, collaborating to the board of evidences and alerts about the organism damages associated to this kind of ectopic fat accumulation. On the other hand, SAT does not show a clear association pattern and can be considered a poor predictor of lung function in this population, showing agreement with the health lifestyle hypothesis linked with subcutaneous fat deposition. 


\section{Additional file}

Additional file 1: Table S1. Association between pulmonary function (z-score) and confounding variables. 1982 Pelotas Birth Cohort $(n=3438)$. (DOCX $58 \mathrm{~kb})$

\section{Abbreviations}

$\mathrm{CT}$ : Computed tomography; FEV ${ }_{1}$ : Forced expiratory volume in the first second; FVC: Forced vital capacity; PF: Pulmonary function; SAT: Subcutaneous adipose tissue; VAT: Visceral adipose tissue; WC: Waist circumference

\section{Acknowledgements}

Not applicable.

\section{Funding}

The 1982 Birth Cohort studies were supported by the Wellcome Trust through the programme entitled Major Awards for Latin America on Health Consequences of Population Change (Grant number: 086974/Z/08/Z). The International Development Research Center, World Health Organization, Overseas Development Administration, European Union, National Support Program for Centers of Excellence (PRONEX), the Brazilian National Research Council (CNPq), and the Brazilian Ministry of Health supported previous phases of the study. We are grateful to the Brazilian government for providing scholarships (a PhD scholarship to PDO).

\section{Availability of data and materials}

The datasets used and analysed during the current study are available from the corresponding author or institution on request.

\section{Authors' contributions}

PDO was the main responsible for the analysis and interpretation of data and drafted the article. AMB, FCW, RP, BLH, FCB, DPG, GVF, KO and ER made substantial contributions to conception, design, and interpretation of data and drafting of the article. FCB, DPG, GVF, KO and ER contributed to acquisition of data and all aspects of the work in ensuring that questions related to the accuracy or integrity of any part of the work were appropriately investigated and resolved. All authors revised the article critically and approved the final version to be published.

\section{Ethics approval and consent to participate}

The 30 years follow-up project was approved by the Federal University of Pelotas Ethics Committee under protocol 16/12. All subjects signed informed consent form.

\section{Consent for publication}

Not applicable.

\section{Competing interests}

AMBM received payment from Aztra Zeneca to carry out analysis of the PUMA study, and was paid by GSK to attend the ERS. RP received personal fees from Novartis for one lecture on epidemiology of COPD. All authors declare that they have no competing of interest related to the subject of this manuscript.

\section{Publisher's Note}

Springer Nature remains neutral with regard to jurisdictional claims in published maps and institutional affiliations.

\section{Author details}

${ }^{1}$ Federal University of Pelotas - Postgraduate Program in Epidemiology, Rua Marechal Deodoro, 1160, $3^{\circ}$ andar, Pelotas, RS Zip code: 96020-220, Brazil. ${ }^{2}$ National Institute of Respiratory Diseases, Calzada De Tlalpan, 4502 Mexico City, DF, Mexico. ${ }^{3}$ Ministry of Health - Secretariat of Health Surveillance, Esplanada dos Ministérios Bloco G, Brasilia, DF Zip code: 70058-900, Brazil. ${ }^{4}$ Catholic University of Pelotas - Postgraduate Program in Health and Behavior, Rua Gonçalves Chaves, 373, Pelotas, RS Zip code: 96015-560, Brazil. ${ }^{5}$ Medical Research Council (MRC) Epidemiology Unit, Institute of Metabolic
Science, University of Cambridge School of Clinical Medicine, Cambridge Biomedical Campus, Cambridge, UK.

Received: 2 August 2017 Accepted: 17 November 2017

Published online: 28 November 2017

\section{References}

1. Littleton SW. Impact of obesity on respiratory function. Respirology. 2012; 17(1):43-9.

2. Sociedade Brasileira de Pneumologia e Tisiologia. Diretrizes para testes de função pulmonar. J Pneumol. 2002;28(s3):S1-S82.

3. Lessard A, Almeras N, Turcotte H, Tremblay A, Despres JP, Boulet LP. Adiposity and pulmonary function: relationship with body fat distribution and systemic inflammation. Clin Invest Med. 2011;34(2):E64-70.

4. Scott HA, Gibson PG, Garg ML, et al. Relationship between body composition, inflammation and lung function in overweight and obese asthma. Respir Res. 2012;13:10.

5. Shuster A, Patlas M, Pinthus JH, Mourtzakis M. The clinical importance of visceral adiposity: a critical review of methods for visceral adipose tissue analysis. Br J Radiol. 2012:85(1009):1-10.

6. Collins LC, Hoberty PD, Walker JF, Fletcher EC, Peiris AN. The effect of body fat distribution on pulmonary function tests. Chest. 1995;107(5):1298-302.

7. Armellini F, Zamboni M, Robbi R, et al. Total and intra-abdominal fat measurements by ultrasound and computerized tomography. Int J Obes Relat Metab Disord. 1993;17(4):209-14.

8. Rasslan Z, Stirbulov R, Junior RS, et al. The impact of abdominal adiposity measured by sonography on the pulmonary function of pre-menopausal females. Multidiscip Respir Med. 2015;10(1):23.

9. Capelo AV, da Fonseca VM, Peixoto MV, et al. Visceral adiposity is associated with cytokines and decrease in lung function in women with persistent asthma. Rev Port Pneumol (2006). 2016;22(5):255-61.

10. Lim S, Kwon SY, Yoon JW, et al. Association between body composition and pulmonary function in elderly people: the Korean longitudinal study on health and aging. Obesity (Silver Spring). 2011;19(3):631-8.

11. Park YS, Kwon HT, Hwang SS, et al. Impact of visceral adiposity measured by abdominal computed tomography on pulmonary function. J Korean Med Sci. 2011:26(6):771-7.

12. Horta BL, Gigante DP, Goncalves H, et al. Cohort profile update: the 1982 Pelotas (Brazil) birth cohort study, Int J Epidemiol. 2015:44(2):441-e.

13. Miller MR, Hankinson J, Brusasco V, et al. Standardisation of spirometry. Eur Respir J. 2005:26(2):319-38.

14. Stolk RP, Wink O, Zelissen PM, Meijer R. Gils APV, Grobbee DE. Validity and reproducibility of ultrasonography for the measurement of intra-abdominal adipose tissue. Int J Obes Relat Metab Disord. 2001;25(9):1346-51.

15. Gradmark AMI, Rydh A, Renström F, Lucia-Rolfe ED, Sleigh A, Nordström $P$ et al. Computed tomography-based validation of abdominal adiposity measurements from ultrasonography, dual-energy X-ray absorptiometry and anthropometry. Br J Nutr. 2010;104:582-8.

16. Araujo de França GV, Rolfe EDL, Horta BL, Gigante DP, Yudkin JS, Ong KK, et al. Genomic ancestry and education level independently influence abdominal fat distributions in a Brazilian admixed population. PLoS One. 2017:12(6):e0179085

17. Araujo de Franca GV, Lucia-Rolfe ED, Horta BL, et al. Associations of birth weight, linear growth and relative weight gain throughout life with abdominal fat depots in adulthood: the 1982 Pelotas (Brazil) birth cohort study. Int J Obes. 2016:40(1):14-21.

18. Barros AJD, Victora CG. Indicador econômico para o Brasil baseado no censo demográfico de 2000. Rev Saude Publica. 2005;39:523-9.

19. Oliveira PD, Wehrmeister FC, Perez-Padilla R, et al. Relationship between body composition and pulmonary function in early adult life: a crosssectional analysis nested in two birth cohort studies. PLoS One. 2016;11(9): e0163428.

20. Sorlí-Aguilar M, Martín-Luján F, Flores-Mateo G, et al. Adiposity markers and lung function in smokers: a cross-sectional study in a Mediterranean population. BMC Pulm Med. 2016:16:178.

21. Vatrella A, Calabrese C, Mattiello A, et al. Abdominal adiposity is an early marker of pulmonary function impairment: findings from a Mediterranean Italian female cohort. Nutr Metab Cardiovasc Dis. 2016;26(7):643-6.

22. De Lucia Rolfe E, Sleigh A, Finucane FM, et al. Ultrasound measurements of visceral and subcutaneous abdominal thickness to predict abdominal 
adiposity among older men and women. Obesity (Silver Spring). 2010;18: 625-31.

23. De Lucia Rolfe E, Norris SA, Sleigh A, et al. Validation of ultrasound estimates of visceral fat in black south African adolescents. Obesity (Silver Spring). 2011;19:1892-7.

24. Rolfe Ede L, Loos RJ, Druet C, et al. Association between birth weight and visceral fat in adults. Am J Clin Nutr. 2010;92:347-52.

25. Neeland IJ, Ayers CR, Rohatgi AK, et al. Associations of visceral and abdominal subcutaneous adipose tissue with markers of cardiac and metabolic risk in obese adults. Obesity. 2013;21:E439-47.

26. Bidulescu A, Liu J, Hickson DA, et al. Gender differences in the association of visceral and subcutaneous adiposity with adiponectin in African Americans: the Jackson heart study. BMC Cardiovasc Disord. 2013;13:9.

27. Foster MC, Hwang SJ, Massaro JM, et al. Association of subcutaneous and visceral adiposity with albuminuria: the Framingham heart study. Obesity. 2011;19:1284-9.

28. Weisberg SP, McCann D, Desai M, et al. Obesity is associated with macrophage accumulation in adipose tissue. J Clin Invest. 2003;112: 1796-808.

29. Yudikin JS, Stehouwer CDA, Emeis JJ, et al. C-reative protein in healthy subjects: associations with obesity, insuline resistence and endothelial disfunction: a potential role for cytokines originating from adipose tissue? Arterioscler Thromb Vasc Biol. 1999;19:972-8.

30. Despres JP, Lemieux I. Abdominal obesity and metabolic syndrome. Nature. 2006;444(7121):881-7.

31. Lovejoy JC, Smith SR, Rood JC. Comparation of regional fat distribution and health risk factors in middle-aged white and african american women: the heathy transtions study. Obes Res. 2001;9(1):10-6.

32. Misra A, Alappan NK, Vikram NK, et al. Effect of supervised progressive resistance-exercise training protocol on insulin sensitivity, glycemia, lipids, and body composition in Asian Indians type 2 diabetes. Diabetes Care. 2008;31(7):1282-7.

33. Liu J, Fox CS, Hickson DA, et al. Impact of abdominal visceral and subcutaneous adipose tissue on cardiometabolic risk factors: the Jackson heart study. J Clin Endocrinol Metab. 2010;95:5419-26.

34. McLaughlin T, Lamendola C, Liu A, et al. Preferential fat deposition in subcutaneous versus visceral depots is associated with insulin sensitivity. J Clin Endocrinol Metab. 2011;96:E1756-E60

35. Porter SA, Massaro JM, Hoffman U, et al. Abdominal subcutaneous adipose tissue: a protective fat depot? Diabetes Care. 2009;32(6):1068-75.

\section{Submit your next manuscript to BioMed Central and we will help you at every step:}

- We accept pre-submission inquiries

- Our selector tool helps you to find the most relevant journal

- We provide round the clock customer support

- Convenient online submission

- Thorough peer review

- Inclusion in PubMed and all major indexing services

- Maximum visibility for your research

Submit your manuscript at www.biomedcentral.com/submit
Biomed Central 